\title{
Irreversible Choice of Uncertain Technologies with Network Externalities
}

\author{
by \\ Jay Pil Choi, Columbia University \\ November 1990, Revised May 1992 \\ Discussion Paper Series No. 612
}

$$
\begin{aligned}
& d p 9293-612 \\
& \text { pages } 28
\end{aligned}
$$




\title{
Irreversible Choice of Uncertain Technologies with Network Externalities
}

\author{
By \\ Jay Pil Choi*
}

\author{
November 1990 \\ revised May 1992
}

*Department of Economics, Columbia University

I would like to thank Jean-Jacques Laffont, Eric Maskin, and Eytan Sheshinsky for their helpful comments and encouragement. An earlier version of this paper was presented in the 1991 Fareastern Meeting of the Econometric Society in Seoul, Korea. Any remaining errors are mine. 


\begin{abstract}
This paper explores the problem of sequential and irreversible technology choice in the presence of network externalities when the technologies stochastically evolve over time. Early potential users are shown to adopt an irreversible technology too early compared to the social optimum. The effect of increasing the uncertainty of the technologies on early potential user's decision is analyzed. We find that the sponsor of new emerging technology might choose too safe a research strategy. We also study the consequences of allowing side payments between generations of consumers, and demonstrate that ex post optimal policy can impair ex ante social welfare.
\end{abstract}




\section{Introduction}

In an environment where technology evolves stochastically over time, potential users making a technology choice must consider whether the best available technology today will remain a good technology in the future; this is especially important when the technology choice is largely an irreversible one. For instance, personal computers are designed around a microprocessor which embodies an architecture that is often proprietary and incompatible with other microprocessors. Apple computers are designed around the "Motorola" microchip. IBM compatibles are built around the 'Intel" microchip while Sun Microsystems workstations are based on the Sun's "Sparc" architecture. After committing to a microprocessor, switching to another one can be extremely costly; it might involve extensive redesign of the product, or a total washout of costs incurred in the development of customized software. Another possibility is retraining cost to get acquainted with the new technology - see Banerjee and Summers (1986), Farrell (1985), and Klemperer (1984) for more on the implications of the costs of switching.

The importance of the technology choice becomes more acute in the presence of network externalities. In this case, the danger of a user choosing the wrong technology is not only that she will have an inferior technology ex post, but also that she faces the possibility of being stranded by other people who adopt a different and incompatible technology. In this paper we investigate the implications of network externalities on the irreversible technology choice when competing and inherently incompatible technologies evolve over time stochastically.

There are two strands of literature related to this paper: one in the area of the optimal stopping rule in an irreversible investment decision problem, and the other in the area of compatibility and standardization. In the irreversible investment literature, McDonald and Siegel (1986) study the optimal timing of investment in an irreversible project where the value of the project follows continuous time stochastic processes in the absence of network externalities - see also Baldwin (1982) and Pindyck (1988). Balcer and Lippman (1984) 
also consider a situation where a firm must decide whether to adopt the best currently available technology or to postpone adoption in anticipation of better technology in the near future. Their focus is not on the externalities exerted upon one generation of consumers by another generation. In the literature of compatibility and network externalities, Farrell and Saloner (1986) investigate the implications of an installed base for the adoption of technologies with network externalities. However, in their model, the new technology becomes available unexpectedly, and as a consequence, the option of waiting is not considered to be an alternative strategy. ${ }^{1}$ Katz and Shapiro (1992) allows the option to wait for consumers in a model of product introduction with network externalities. The value of technology changes over time in their model, but it is known with certainty in advance. As a consequence, in their perfect foresight equilibria, consumers never exercise their option to wait. Moreover, their focus is on the supplier. In particular, the timing of product introduction and the incentive to achieve compatibilities with the installed base are examined. In contrast to this paper, Choi (1990) and Waldman (1989) analyze the case where the technology choice is not irreversible and consumers are allowed to make repeat purchases. In that context, they provide a formal theory of planned obsolescence based on incompatible technologies in the presence of network externalities.

The paper is organized in the following way. In section II, we outline the formal model. Then, we study the pattern of technology adoption that would be induced by private agents, and compare this outcome with the outcome induced by a welfaremaximizing social planner. Section III deals with a special case where a newly emerging technology is competing with an established and mature one. We also analyze a situation in which new technology is sponsored and the sponsor of it can choose the riskiness of research strategy. In section IV we allow side payments between generations of consumers

${ }^{1}$ They, however, allow the possibility of waiting by consumers in the analysis of product pre-announcements. 
and and examine the ex ante welfare implication of ex post policy intervention. Concluding remarks follow.

\section{The Model}

In this section, we lay out a general formulation of the model and study the users' coordination problem in adopting irreversible technologies exhibiting network externalities. There are two time periods, $t=1,2$. There are also two potential users, 1 and 2 , who arrive sequentially at time $t=1$ and 2 , respectively. Potential user 1 will be referred to as an earlycomer and 2, as a latecomer. There exist two competing incompatible technologies $\mathrm{A}$ and B. In period 1, the earlycomer contemplates choosing one of available technologies. She has three options from which to choose. One is to choose technology A, and another is to choose B. The third option is to wait until period 2 when she can make an optimal choice given how the technologies have evolved. In period 2, a new potential consumer 2 arrives on the scene and makes a technology adoption choice, given the choice of user 1 . The discount factor is given by $\delta$. The value of each technology is revealed at the beginning of each period and evolves stochastically. More specifically, the value of each technology in period 1 is given by $\alpha_{1}$ and $\beta_{1}$, respectively, if the technology is used by only one player (stand-alone benefit). The stand-alone values of technologies in period 2 are random variables from the viewpoint of a potential adopter in period 1 , which will be revealed at the beginning of period 2. The stochastic nature of the value of technology can be considered to be due to the uncertain availability of complementary or substitute goods. Another possibility is that the potential value of a technology is very hard to predict in the early stage of development. For our purpose, the process of technology evolution is an exogenous one independent of any buyer's decision. ${ }^{2}$ The type of research performed at

2This is not an innocuous assumption since new knowledge can be generated by the use of a specific product (learning by using). See Rosenberg (1982) for an illuminating analysis and evidence on economic activities involving learning. 
universities or funded by government, the outcome of which is supplied competitively, would fall in this category. ${ }^{3}$ Denoting by $\tilde{\alpha}_{2}$ and $\tilde{\beta}_{2}$ the values of each technology in period 2, we assume that they are nonnegative real numbers with common support, $[0$, v. ${ }^{4}$ There is a joint probability distribution of the value of technologies, $G\left(\tilde{\alpha}_{2}, \tilde{\beta}_{2}\right)$. We also denote by $\Delta$, the value each user attaches to the network externalities conferred when the other user adopts the same technology. That is, if the consumer adopts technology A (B) alone, then his benefit from the technology is given by $\tilde{\alpha}_{2}\left(\tilde{\beta}_{2}\right)$ while he derives the benefit of $\tilde{\alpha}_{2}+\Delta\left(\tilde{\beta}_{2}+\Delta\right)$ if the other user also adopts technology $A(B)$. Here, we assume symmetry in the value each user attaches to compatibility. The basic results in this paper hold if asymmetry is allowed. Also, the assumption of only one user arriving in each period should not be considered a limitation of this model. If we allowed a cohort of $\mathrm{N}_{1}$ and $\mathrm{N}_{2}$ people to arrive in the first and in the second period, the analysis would be almost identical to the one in this paper, provided that the assumption of coordination on the Pareto-superior outcome within -the-period is maintained. This extension of the model would only lead to minor changes in the interpretation of the results.

\section{A. Market Outcome}

Now consider how the technology adoption decisions unfold in the market place. Let $\Omega=\left\{\left(\tilde{\alpha}_{2}, \widetilde{\beta}_{2}\right) ;\left(\tilde{\alpha}_{2}, \widetilde{\beta}_{2}\right) \in[0, \bar{v}]^{2}\right\}$ be the sample space of the values of the technologies in period 2. Define the following sets:

$$
E_{0}=\left\{\left(\tilde{\alpha}_{2}, \widetilde{\beta}_{2}\right) ; \tilde{\alpha}_{2} \geq \tilde{\beta}_{2}, \quad\left(\tilde{\alpha}_{2}, \tilde{\beta}_{2}\right) \in\left[0, v^{2}\right\}\right.
$$

3In the terminology of Katz and Shapiro (1986), the technology is nonsponsored. See section III, however, for the case of sponsored technology.

${ }^{4}$ More generally, $\tilde{\alpha}_{2}$ and $\tilde{\beta}_{2}$ can take negative values. The value of each technology can be restricted to be greater than or equal to zero, since the user has the option of not using the technology. If we embrace this interpretation, the (marginal) distribution of the value of each of the technologies would be a mix of the original distribution truncated below zero and atom at zero. 


$$
\begin{aligned}
& E_{1}=\left\{\left(\tilde{\alpha}_{2}, \tilde{\beta}_{2}\right) ; \tilde{\alpha}_{2}+\Delta \geq \tilde{\beta}_{2},\left(\tilde{\alpha}_{2}, \tilde{\beta}_{2}\right) \in[0, \bar{v}]^{2}\right\} \\
& E_{2}=\left\{\left(\tilde{\alpha}_{2}, \tilde{\beta}_{2}\right) ; \tilde{\alpha}_{2}+2 \Delta \geq \tilde{\beta}_{2},\left(\tilde{\alpha}_{2}, \tilde{\beta}_{2}\right) \in[0, \bar{v}]^{2}\right\}
\end{aligned}
$$

The complement of a set $\mathrm{E}$ with respect to the space $\Omega$ will be denoted by $\mathrm{E}^{\mathrm{c}}$. Note that $E_{0} \subseteq E_{1} \subseteq E_{2}$, and $\left(E_{2}-E_{1}\right)=\left(E_{1}^{c}-E_{2}^{c}\right)=\left\{\left(\tilde{\alpha}_{2}, \tilde{\beta}_{2}\right) ; \tilde{\alpha}_{2}+2 \Delta \geq \tilde{\beta}_{2}>\tilde{\alpha}_{2}+\Delta,\left(\tilde{\alpha}_{2}\right.\right.$, $\left.\left.\widetilde{\beta}_{2}\right) \in[0, \bar{v}]^{2}\right\}$.

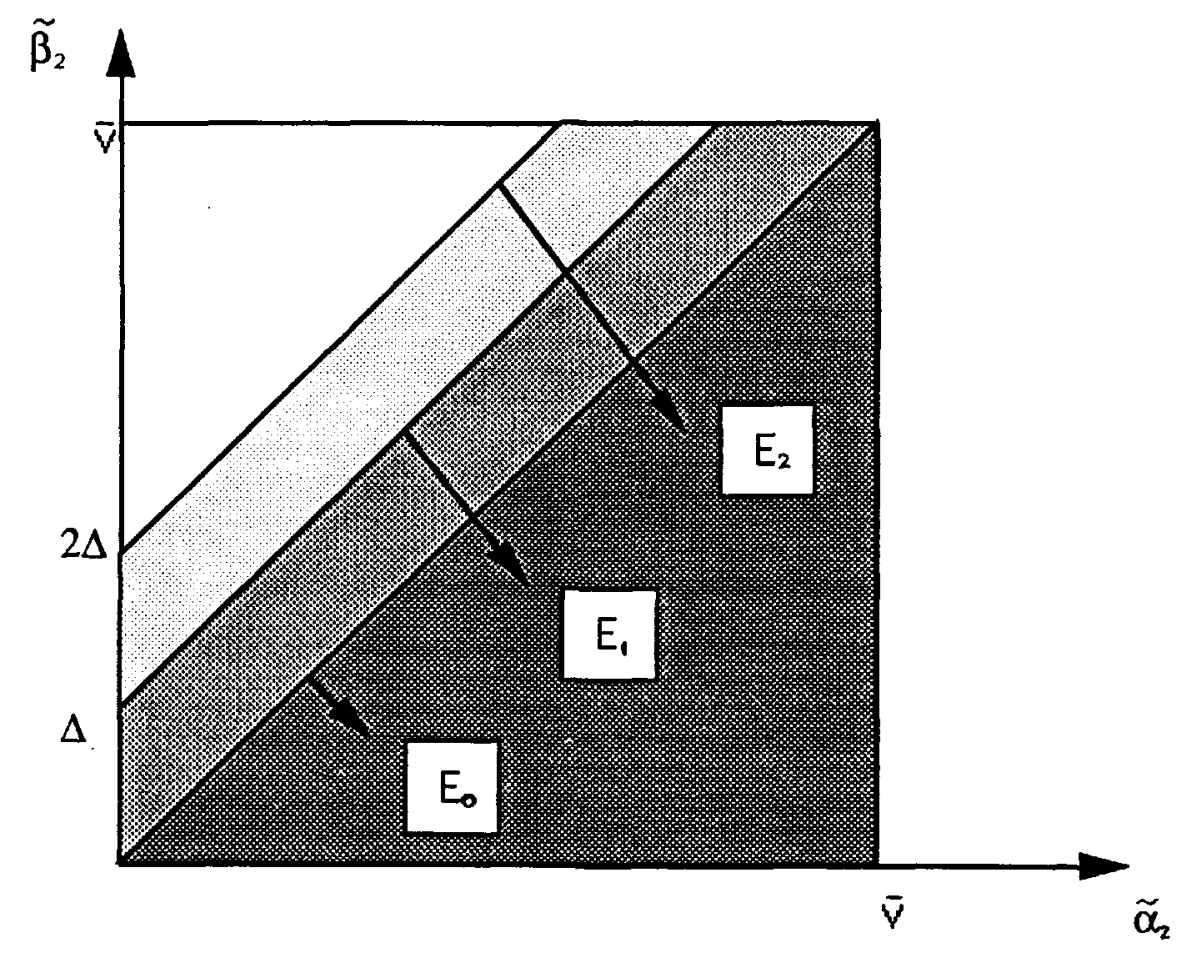

Figure 1. Definition of Relevant Sets in the Space of the Values of Technologies

We solve the problem by backward induction. Suppose that user 1 has adopted technology A in the first period. Then user 2 also adopts technology A if and only if (1)

$$
\tilde{\alpha}_{2}+\Delta \geq \tilde{\beta}_{2}
$$


i.e., the realizations of the technology values belong to set $E_{1}$. Otherwise, user 2 will adopt technology B. We can derive a similar condition in the case where user 1 has adopted technology $\mathrm{B}$ in period 1.

Now consider the situation where user 1 has decided to delay adoption until period 2. There are two cases to examine. If $\left|\widetilde{\beta}_{2}-\tilde{\alpha}_{2}\right| \geq \Delta$, then the dominant strategy for each player is to choose the technology whose stand alone benefit is higher. If $\left|\tilde{\beta}_{2}-\tilde{\alpha}_{2}\right|<\Delta$, then the difference in the stand alone benefit is not great enough for each player to make a technology choice regardless of the choice of the other. There are two Nash equilibria. One has both players choosing technology $\mathrm{A}$, and the other has both players choosing technology B. However, these two equilibria are Pareto-comparable. We will assume that players can coordinate their choices within the period, so that they can end up with a Pareto-optimal choice. 5 The consequence of this assumption is that technology A will be adopted if $\mathrm{E}_{0}$ occurs and $\mathrm{B}$ will be adopted if $\mathrm{E}_{0}{ }^{\mathrm{C}}$ occurs. There is always a benefit from the network externality, since compatibility is always achieved, provided that the early adoptor has chosen the option of waiting.

Given the equilibrium outcome of the second period for each subgame, we are ready to investigate the optimal decision of user 1 in period 1 . If she decides to wait until period 2, then her expected payoff is given by,

$$
\begin{aligned}
\mathrm{V}(\mathrm{W}) & =\delta \mathrm{E}\left[\max \left(\tilde{\alpha}_{2}, \tilde{\beta}_{2}\right)+\Delta\right] \\
& =\delta \Delta+\delta\left[\int_{\mathrm{E}_{0}} \tilde{\alpha}_{2} \mathrm{dG}\left(\tilde{\alpha}_{2}, \tilde{\beta}_{2}\right)+\int_{\mathrm{E}_{0}^{\mathrm{c}}} \tilde{\beta}_{2} \mathrm{dG}\left(\tilde{\alpha}_{2}, \tilde{\beta}_{2}\right)\right]
\end{aligned}
$$

If she adopts technology $\mathrm{A}$ in the first period, then her expected payoffs are given by

5 One way to justify this within the period coordination assumption would be to introduce an intertemporal structure to the technology adoption process within the period. If the consumers make adoption decisions in a predetermined order, then the Pareto-optimal outcome would be the only subgame perfect equilibrium with complete information. See Farrell and Saloner (1985) for details. 


$$
\begin{aligned}
\mathrm{V}(\mathrm{A}) & =\alpha_{1}+\delta \mathrm{E}\left\{\left(\tilde{\alpha}_{2}+\Delta\right) \mathrm{I}_{\mathrm{E}_{1}}\left[\left(\tilde{\alpha}_{2}, \tilde{\beta}_{2}\right)\right]+\tilde{\alpha}_{2} \mathrm{I}_{\mathrm{E}_{1}^{\mathrm{c}}}^{\mathrm{c}}\left[\left(\tilde{\alpha}_{2}, \tilde{\beta}_{2}\right)\right]\right\} \\
& =\alpha_{1}+\delta\left[\int_{\mathrm{E}_{1}}\left(\tilde{\alpha}_{2}+\Delta\right) \mathrm{dG}\left(\tilde{\alpha}_{2}, \tilde{\beta}_{2}\right)+\int_{\mathrm{E}_{1}^{\mathrm{c}}} \tilde{\alpha}_{2} \mathrm{dG}\left(\tilde{\alpha}_{2}, \tilde{\beta}_{2}\right)\right]
\end{aligned}
$$

where I [.] is an indicator function. Similarly, her expected payoff from adopting technology $B$ in the first period is given by,

$$
\left.\mathrm{V}(\mathrm{B})=\beta_{1}+\delta \mathrm{E}\left\{\left(\tilde{\beta}_{2}+\Delta\right) \mathbf{I}_{\left[\tilde{\beta}_{2}\right.}+\Delta \geq \tilde{\alpha}_{2]}\left[\left(\tilde{\alpha}_{2}, \tilde{\beta}_{2}\right)\right]+\widetilde{\beta}_{2} \mathbf{I}_{\left[\tilde{\beta}_{2}\right.}+\Delta<\tilde{\alpha}_{2}\right]\left[\left(\tilde{\alpha}_{2}, \tilde{\beta}_{2}\right)\right]\right\}
$$

She will compare $V(W), V(A)$, and $V(B)$, and select the strategy which gives her the highest expected payoffs.

\section{B. Social Optimum}

Now consider the optimal choice of technology from the social planner's viewpoint. Social welfare is defined by the sum of the utilities of two potential users. First consider the socially optimal decision in the second period given the choice of the first period. If user 1 has made an irreversible choice of $A$ in period 1 , then the socially optimal choice by user 2 is also $A$, if and only if $2\left(\tilde{\alpha}_{2}+\Delta\right) \geq \tilde{\alpha}_{2}+\widetilde{\beta}_{2}$, i.e.,

$$
\tilde{\alpha}_{2}+2 \Delta \geq \tilde{\beta}_{2}
$$

The social optimum dictates that the same technology A be adopted by the second period user if (and only if) the value of technologies lie in set $E_{2}$, while the same technology is adopted in the market equilibrium if (and only if) the value of technologies lie in set $E_{1}$. The discrepancy arises from the fact that user 2 does not take into account the negative externalities he imposes on user 1 by adopting the incompatible technology forcing user 2 to be stranded away. Another interpretation is that user 2 does not consider the positive network externalities he confers on user 1 by adopting the same technology. Since $\mathrm{E}_{1} \subseteq$ 
$E_{2}$, the market outcome induces user 2 to adopt the technology which is incompatible to that chosen by user 1 in more cases than the social optimum dictates. ${ }^{6}$

If user 1 deferred her decision, then the socially optimal choice in period 2 is to choose the best technology available at that time and is the same as the individually optimal choice.

We now consider the "first-best" benchmark. We search for the socially optimal decision by user 1 in the first period, given that the second period technology choice is also made in a socially optimal way. If user 1 waits in the first period, the expected social surplus is given by

$$
\mathrm{S}(\mathrm{W})=2 \delta \mathrm{E}\left[\max \left(\tilde{\alpha}_{2}, \tilde{\beta}_{2}\right)+\Delta\right]=2 \mathrm{~V}(\mathrm{~W})
$$

If user 1 adopts one of the two technologies, then the expected social surplus is given by

$$
\begin{aligned}
S(A)= & \alpha_{1}+\delta \mathrm{E}\left\{2\left(\tilde{\alpha}_{2}+\Delta\right) \mathbf{I}_{\mathrm{E}_{2}}\left[\left(\tilde{\alpha}_{2}, \tilde{\beta}_{2}\right)\right]+\left(\tilde{\alpha}_{2}+\tilde{\beta}_{2}\right) \mathbf{I}_{\mathrm{E}_{2}^{c}}\left[\left(\tilde{\alpha}_{2}, \tilde{\beta}_{2}\right)\right]\right\} \\
= & \alpha 1+\delta\left[2 \int_{\mathrm{E}_{2}}\left(\tilde{\alpha}_{2}+\Delta\right) \operatorname{dG}\left(\tilde{\alpha}_{2}, \tilde{\beta}_{2}\right)+\int_{\mathrm{E}_{2}^{c}}\left(\tilde{\alpha}_{2}+\tilde{\beta}_{2}\right) \operatorname{dG}\left(\tilde{\alpha}_{2}, \tilde{\beta}_{2}\right)\right] \\
S(B)= & \beta_{1}+\delta \mathrm{E}\left\{2\left(\tilde{\beta}_{2}+\Delta\right) \mathbf{I}_{\left[\tilde{\beta}_{2}+2 \Delta \geq \tilde{\alpha}_{2}\right]}\left[\left(\tilde{\alpha}_{2}, \tilde{\beta}_{2}\right)\right]\right. \\
& \left.\left.+\left(\tilde{\alpha}_{2}+\tilde{\beta}_{2}\right) \mathbf{I}_{\left[\tilde{\beta}_{2}\right.}+2 \Delta<\tilde{\alpha}_{2}\right]\left[\left(\tilde{\alpha}_{2}, \tilde{\beta}_{2}\right)\right]\right\}
\end{aligned}
$$

We say that an outcome is efficient if it maximizes the net social payoff among (5) - (7).

There are two opposing forces which lead the private decision in the first period to diverge from the socially optimal decision in the first period. First, user 1 confers positive externalities on user 2 by waiting. If she waits, there is always a compatibility based positive network externality, since both users can coordinate to choose the same technology in period 2; note that they will choose the best technology available in period 2 .

\footnotetext{
6 The phenomenon of inefficient stranding is referred to as excess momentum in Farrell and
} Saloner (1986). 
However, if she adopts, for example, technology A, then compatibility is achieved only when the event $E_{2}$ occurs in the socially optimal outcome. There are two kinds of negative externalities imposed on user 2 by adopting in period 1. First, in the event of $E_{2}{ }^{c}$, user 2 will not reap the benefit of the network externality, $\Delta$. Second, in the event of $\left(E_{2}-\right.$ $E_{0}$ ), an inferior technology will be chosen by user 2 to ensure compatibility with the installed technology of user 1 . Since user 1 ignores these externalities, there is a tendency for the first period consumer to adopt one of the technologies too early compared to the social optimum. Second, there is an opposing factor which induces user 1 to delay her technology adoption compared to the social optimum. If she adopts one of the technologies in the first period (say A), then the probability of being stranded by user 2 is larger in the market outcome than in the socially optimal one since $E_{1} \subseteq E_{2}$. We may say that the cost of adopting the wrong technology in the first period is less costly in the socially optimal outcome since compatibility can be achieved in the wider circumstances. Therefore, the option of waiting is more attractive under the market outcome, ceteris paribus. Whether the technology adoption choice would be made too soon or too late depends on the magnitude of these three effects. The following proposition, however, shows that the first two effects dominate the third in the case of ex ante identical technologies.

Proposition 1 Suppose that the two technologies are ex ante symmetric, that is $\alpha_{1}=\beta_{1}$, and $\mathrm{G}\left(\tilde{\alpha}_{2}, \widetilde{\beta}_{2}\right)=\mathrm{G}\left(\tilde{\beta}_{2}, \tilde{\alpha}_{2}\right)$. Then, there is a tendency for the earlycomer to adopt a technology too soon.

Proof. We would like to show that $S(W)-S(A) \geq V(W)-V(A)$ so that the incentive for the society to wait until period 2 is greater than that for individual decision maker. For that purpose, it is sufficient to have $[S(W)-V(W)]-[S(A)-V(A)] \geq 0$. Note that $E_{0} \subseteq E_{1} \subseteq$ $E_{2}$, and $\left(E_{2}-E_{1}\right)=\left(E_{1}^{c}-E_{2}^{c}\right)=\left\{\left(\tilde{\alpha}_{2}, \tilde{\beta}_{2}\right) ; \tilde{\alpha}_{2}+2 \Delta \geq \tilde{\beta}_{2} \geq \tilde{\alpha}_{2}+\Delta,\left(\tilde{\alpha}_{2}, \tilde{\beta}_{2}\right) \in[0\right.$, v $]^{2}$. 


$$
\begin{aligned}
& \delta^{-1}[\mathrm{~S}(\mathrm{~W})-\mathrm{V}(\mathrm{W})]=\mathrm{E}\left[\max \left(\tilde{\alpha}_{2}, \tilde{\beta}_{2}\right)+\Delta\right] \\
& =\Delta+\left[\int_{\mathrm{E}_{0}} \tilde{\alpha}_{2} \mathrm{dG}\left(\tilde{\alpha}_{2}, \tilde{\beta}_{2}\right)+\int_{\mathrm{E}_{2}-\mathbf{E}_{0}} \tilde{\beta}_{2} \mathrm{dG}\left(\tilde{\alpha}_{2}, \tilde{\beta}_{2}\right)+\int_{\mathrm{E}_{2}^{\mathbf{c}}} \tilde{\beta}_{2} \mathrm{dG}\left(\tilde{\alpha}_{2}, \tilde{\beta}_{2}\right)\right] \\
& \delta^{-1}[\mathrm{~S}(\mathrm{~A})-\mathrm{V}(\mathrm{A})]= \\
& {\left[2 \int_{\mathrm{E}_{2}}\left(\tilde{\alpha}_{2}+\Delta\right) \mathrm{dG}\left(\tilde{\alpha_{2}}, \tilde{\beta}_{2}\right)+\int_{\mathrm{E}_{2}^{\mathrm{c}}}\left(\tilde{\alpha}_{2}+\tilde{\beta}_{2}\right) \mathrm{dG}\left(\tilde{\alpha}_{2}, \tilde{\beta}_{2}\right)\right]-\left[\int_{\mathrm{E}_{1}}\left(\tilde{\alpha}_{2}+\Delta\right) \mathrm{dG}\left(\tilde{\alpha}_{2}, \tilde{\beta}_{2}\right)+\int_{\mathrm{E}_{1}^{\mathbf{c}}} \tilde{\alpha}_{2} \mathrm{dG}\left(\tilde{\alpha}_{2}, \tilde{\beta}_{2}\right)\right]} \\
& =\int_{\mathrm{E}_{2}} \tilde{\alpha}_{2} \mathrm{dG}\left(\tilde{\alpha}_{2}, \tilde{\beta}_{2}\right)+\int_{\mathbf{E}_{2}^{\mathrm{c}}} \tilde{\beta}_{2} \mathrm{dG}\left(\tilde{\alpha}_{2}, \tilde{\beta}_{2}\right)+\int_{\mathrm{E}_{2}} \Delta \mathrm{dG}\left(\tilde{\alpha}_{2}, \tilde{\beta}_{2}\right)+\int_{\mathbf{E}_{2}-\mathbf{E}_{1}} \Delta \mathrm{dG}\left(\tilde{\alpha}_{2}, \tilde{\beta}_{2}\right)
\end{aligned}
$$

Therefore,

$$
[S(W)-V(W)]-[S(A)-V(A)]
$$$$
=\delta\left[\int_{\mathbf{E}_{2}^{c}} \Delta \mathrm{dG}\left(\tilde{\alpha}_{2}, \tilde{\beta}_{2}\right)+\int_{\mathbf{E}_{2}-\mathbf{E}_{0}}\left(\tilde{\beta}_{2}-\tilde{\alpha}_{2}\right) \mathrm{dG}\left(\tilde{\alpha}_{2}, \tilde{\beta}_{2}\right)-\int_{\mathbf{E}_{2}-\mathbf{E}_{1}} \Delta \mathrm{dG}\left(\tilde{\alpha}_{2}, \tilde{\beta}_{2}\right)\right]
$$

The first two terms in the square bracket represent the negative externalities on user 2 when user 1 decides to adopt technology $A$ in the first period; user 1 does not take these externalities into account in her decision process. The first term is the lost benefit of network externalities by having user 1 adopt the ex post wrong technology. The second term is the expected loss for user 2 from being forced to choose an inferior technology to ensure compatibility with the installed base. These two effects will induce user 1 to adopt technology A too early compared to the social optimum. The last term represents the difference between the socially optimal outcome and the market outcome in the expected value of adopting technology A. Since compatibility is achieved with a smaller probability event in the market outcome $\left(E_{1}\right.$ vs. $\left.E_{2}\right)$, the cost of choosing the wrong technology $e x$ post is more detrimental compared to the socially optimal outcome. The last effect offsets 
the first two effects, causing the option of waiting to be more attractive in the market outcome. However, we show that the second effect alone dominates the third one, leading to too early adoption in the market solution.

Since the first term is positive and $\left.\left[E_{2}-E_{1}\right] \subseteq\left[E_{2}-E_{0}\right]\right)$, we have $[S(W)-V(W)]-[S(A)-V(A)]$

$\geq \delta\left[\int_{E_{2}-E_{1}}\left(\tilde{\beta}_{2}-\tilde{\alpha}_{2}\right) \mathrm{dG}\left(\tilde{\alpha}_{2}, \tilde{\beta}_{2}\right)-\int_{E_{2}-E_{1}} \Delta \mathrm{dG}\left(\tilde{\alpha}_{2}, \tilde{\beta}_{2}\right)\right]$ $\geq 0\left(\right.$ since $\left.\left[E_{2}-E_{1}\right]=\left\{\left(\tilde{\alpha}_{2}, \tilde{\beta}_{2}\right) ; \Delta<\widetilde{\beta}_{2}-\tilde{\alpha}_{2} \leq 2 \Delta, \tilde{\alpha}_{2}, \widetilde{\beta}_{2} \geq 0\right\}\right)$

\section{Special Case: Pre-established vs. Emerging Technology}

Let us assume that $\tilde{\alpha}_{2}=\alpha_{1}=\alpha>0, \beta_{1}=0$ and that $\tilde{\beta}_{2}$ has a probability distribution of $F($.$) . We can interpret technology A$ as pre-established and mature, and $B$ as an emerging technology, the future value of which is unknown in the first period. Note that in this case the waiting option dominates the choice of technology B in the first period. In this section, we will consider two possible property right regimes for technology B: one in which it is sponsored, and the other one in which it is not. We, however, maintain the assumption that technology $\mathrm{A}$ is competitively supplied.

\section{A. Nonsponsored Emerging Technology}

Proposition 2. The social welfare in the first-best outcome $\left(\mathrm{SW}_{\mathrm{F}}\right)$ increases with a mean preserving spread (Rothschild and Stiglitz (1970)) in the distribution of $\widetilde{\beta}_{2}$.

Proof. We prove by showing that both the social value of waiting and adopting technology $\mathrm{A}$ increase. Let $\mathrm{V}(\mathrm{W} ; \mathrm{F})$ be the private value of waiting when the distribution of $\widetilde{\beta}_{2}$ is given by $F($.$) . Then,$ 


$$
\mathrm{V}(\mathrm{W} ; \mathrm{F})=\delta \Delta+\delta\left[\alpha \mathrm{F}(\alpha)+\int_{\alpha}^{\infty} \widetilde{\beta}_{2} \mathrm{dF}\left(\widetilde{\beta}_{2}\right)\right]
$$

Let $F_{2}$ be a mean-preserving spread of $\tilde{\beta}_{2}$ with distribution $F_{1}$. In other words, for all $x \in[0, \bar{v}]$,

$$
\int_{0}^{x} F_{2}\left(\tilde{\beta}_{2}\right) d \tilde{\beta}_{2} \geq \int_{0}^{x} F_{1}\left(\tilde{\beta}_{2}\right) d \tilde{\beta}_{2}
$$

$\delta\left[\mathrm{V}\left(\mathrm{W} ; \mathrm{F}_{2}\right)-\mathrm{V}\left(\mathrm{W} ; \mathrm{F}_{1}\right)\right]=\alpha\left[\mathrm{F}_{2}(\alpha)-\mathrm{F}_{1}(\alpha)\right]+\int_{\alpha}^{\infty} \tilde{\beta}_{2} \mathrm{dF} \mathrm{F}_{2}\left(\tilde{\beta}_{2}\right)-\int_{\alpha}^{\infty} \tilde{\beta}_{2} \mathrm{dF} \mathrm{F}_{1}\left(\tilde{\beta}_{2}\right)$

Note that

$$
\begin{aligned}
& \int_{\alpha}^{\infty} \tilde{\beta}_{2} d F_{2}\left(\tilde{\beta}_{2}\right)-\int_{\alpha}^{\infty} \tilde{\beta}_{2} d F_{1}\left(\tilde{\beta}_{2}\right) \\
& =\left[\int_{-\infty}^{\infty} \tilde{\beta}_{2} \mathrm{dF}_{2}\left(\tilde{\beta}_{2}\right)-\int_{\alpha}^{\infty} \tilde{\beta}_{2} \mathrm{dF}_{2}\left(\tilde{\beta}_{2}\right)\right]-\left[\int_{-\infty}^{\infty} \tilde{\beta}_{2} \mathrm{dF}_{1}\left(\tilde{\beta}_{2}\right)-\int_{\alpha}^{\infty} \tilde{\beta}_{2} \mathrm{dF}_{1}\left(\tilde{\beta}_{2}\right)\right] \\
& =\int_{-\infty}^{\alpha} \tilde{\beta}_{2} \mathrm{dF}_{1}\left(\tilde{\beta}_{2}\right)-\int_{-\infty}^{\alpha} \tilde{\beta}_{2} \mathrm{dF}_{2}\left(\tilde{\beta}_{2}\right) \text { (since } \int_{-\infty}^{\infty} \tilde{\beta}_{2} \mathrm{dF}_{1}\left(\tilde{\beta}_{2}\right)=\int_{-}^{-} \tilde{\beta}_{2} \mathrm{dF}_{2}\left(\tilde{\beta}_{2}\right) \text { ) } \\
& =\left[\alpha F_{1}(\alpha)-\int_{-\infty}^{\alpha} F_{1}\left(\tilde{\beta}_{2}\right) d \tilde{\beta}_{2}\right]-\left[\alpha F_{2}(\alpha)-\int_{-}^{\alpha} F_{2}\left(\tilde{\beta}_{2}\right) d \tilde{\beta}_{2}\right]
\end{aligned}
$$

Therefore,

$\left[V\left(W ; F_{2}\right)-V\left(W ; F_{1}\right)\right]=\delta\left[\int_{-}^{\alpha} F_{2}\left(\tilde{\beta}_{2}\right) d \tilde{\beta}_{2}-\int_{-}^{\alpha} F_{1}\left(\tilde{\beta}_{2}\right) d \tilde{\beta}_{2}\right] \geq 0$

Since the social value of waiting is two times the private value of waiting, $\left[\mathrm{S}\left(\mathrm{W} ; \mathrm{F}_{2}\right)\right.$ $\left.\mathrm{S}\left(\mathrm{W} ; \mathrm{F}_{1}\right)\right] \geq 0$. 
The social value of adopting the technology A (when the second period adoptor follows the first best rule), $S(A ; F)$ is given by,

$$
\mathrm{S}(\mathrm{A} ; \mathrm{F})=\alpha+\delta \alpha+\delta\left[(\alpha+2 \Delta) \mathrm{F}(\alpha+2 \Delta)+\int_{\alpha+2 \Delta}^{\infty} \tilde{\beta}_{2} \mathrm{dF}\left(\tilde{\beta}_{2}\right)\right]
$$

The rest of the proof is similar to the argument above, and therefore is omitted.

The intuition behind Proposition 2 can be understood by noting that technology $\mathrm{A}$ plays the role of a backstop technology when user 1 decides to wait and see how technology B develops. Technology B is useful only when the value of technology B is greater than that of A. Figure 2 depicts the value of waiting as a function of the realization of $\widetilde{\beta}_{2}$, conditional on the value of $\alpha$. The utility function is convex in the value of $\tilde{\beta}_{2}$, and preferences exhibit the property of risk-loving. This so-called "option effect" explains why increasing the weight in the upper tail of the distribution of $\tilde{\beta}_{2}$ by an increase in MPS enhances the value of waiting (see Bhattacharya and Mookherjee (1986) for a related result).

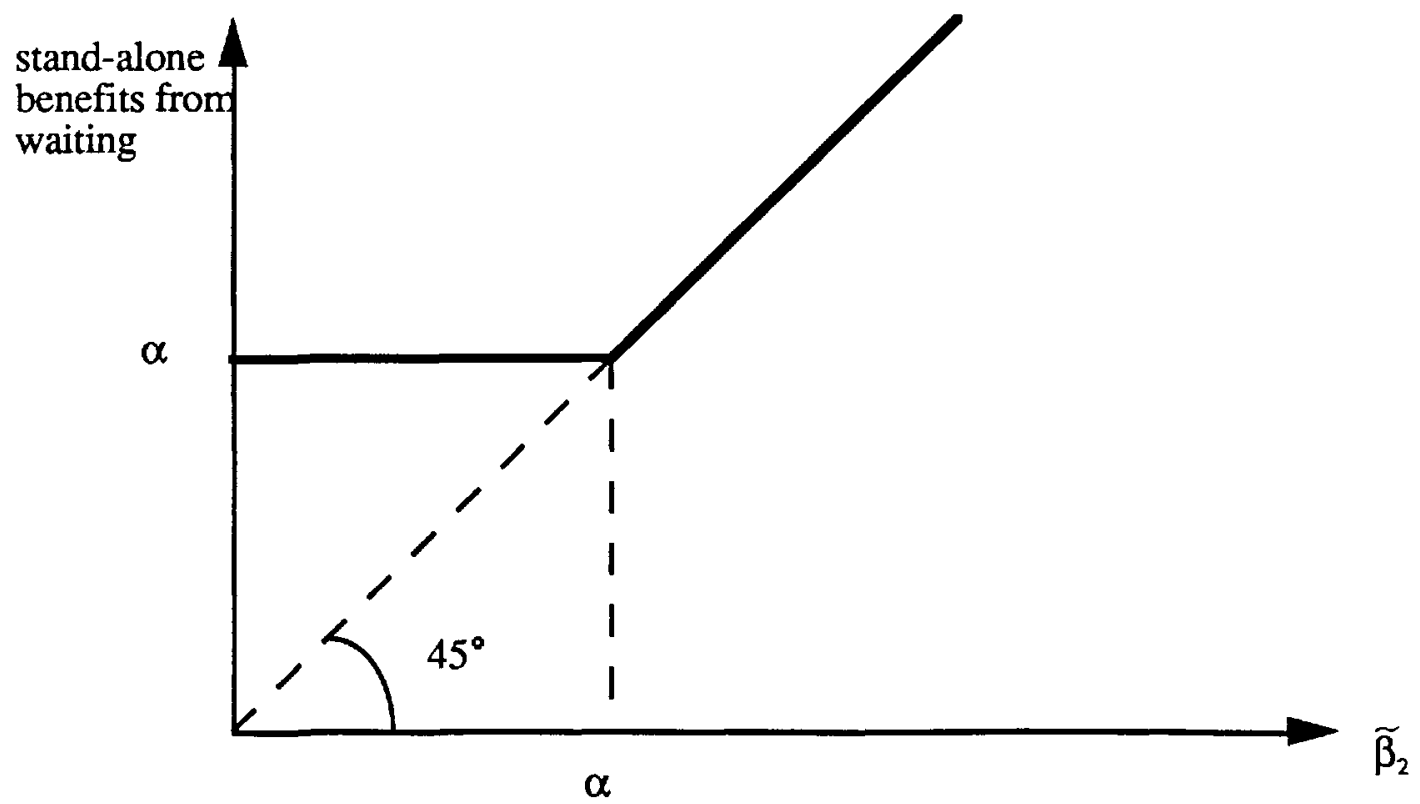

Figure 2. Stand-alone Benefits of Waiting, Given the Value of Technology A, $\alpha$. 
Corollary 1. The private value of waiting also increases with an increase in the MPS.

We can also define the market-induced social welfare $\left(\mathrm{SW}_{\mathrm{M}}\right)$ from each decision in the first period, in which the social welfare is calculated by assuming that the second-period decision is made in an individually optimal way. In a similar way, we can also prove the following:

Corollary 2. The market-induced social welfare $\left(\mathrm{SW}_{\mathrm{M}}\right)$ also increases with a mean preserving spread in the distribution of $\tilde{\beta}_{2}$.

\section{B. Sponsored Emerging Technology}

So far, we have assumed that the technologies are in the public domain and that they are supplied competitively. Now we assume that the emerging technology is being developed by a monopolist who has an exclusive right to the technology, perhaps due to patent protection or proprietary knowledge. We also allow the possibility that the choice of research strategy, $\theta$, by the monopolist can affect the distribution of the research outcome, $\mathrm{F}\left(\tilde{\beta}_{2} ; \theta\right)$. More specifically, increasing $\theta$ increases the riskiness of the outcome. We $\sim$

interpret $\beta_{2}$ as the value of the technology net of constant marginal cost. The first period consumer observes the choice of $\theta$ by the monopolist, and makes her own technology adoption decision.

Here, we ask the following question: will the monopolist choose socially optimal research strategies? Dasgupta and Stiglitz (1980) were the first to ask the same question in the context of entrepreneurs engaged in a "winner-takes-all" patent race. Klette and de Meza (1986), Bhattacharya and Mookherjee (1986), and Dasgupta and Maskin (1987) also studied the optimal choice of riskiness in research strategies. They contend that the market outcome is typically riskier than the socially optimal one. Our result demonstrates that the previous findings do not necessarily hold in the presence of network extemalities. The incentive constraint limits the riskiness of the research strategy. 
When user 1 adopts technology A, the monopolist in the second period must give user 2 at least the value of $\alpha_{1}+\Delta$ in order to provide user 2 with the incentive to buy its technology. Therefore, there will be incompatible technologies only when $\tilde{\beta}_{2}>\alpha_{1}+\Delta$; in this case the monopolist will make a profit of $\tilde{\beta}_{2}-\left(\alpha_{1}+\Delta\right)$. When user 1 waits, technology B competes with A on the level field since there is no installed base. The monopolist can sell his technology with positive profit if $\tilde{\beta}_{2}>\alpha_{1}$. The monopolist will charge a price up to the point where consumers are indifferent between $A$ and $B$ ( or B is slightly preferred to $A$ ) and make a profit of $2\left(\widetilde{\beta}_{2}-\alpha_{1}\right)$. Even though there is transfer of money from consumers to the monopolist, the technology choice pattern in the second period is independent of property right regimes. Since a pure transfer of money among participants of society cancels out in welfare calculations, the social value of waiting and adopting technology $\mathrm{A}$ is also independent of property right regimes. Therefore, we can conclude that social welfare, regardless of whether the technology choices are made by private agents or by the social planner, increases with the MPS when there is sponsored technology.

Proposition 3. The social optimum entails the choice of the riskiest research strategy by the monopolist.

In contrast, the private value of waiting does not depend on the research strategy chosen by the monopolist. When the early adoptor decides to wait, there is no installed base in the second period. Therefore, technology A will be adopted by both consumers if $\tilde{\beta}_{2}<\alpha_{1}$. Otherwise, the monopolist will charge a price of $\left(\widetilde{\beta}_{2}-\alpha_{1}\right)$ and consumers will be indifferent between technologies $A$ and $B$. The value of waiting is independent of the research technology, and is given by $\mathrm{V}(\mathrm{W})=\delta\left(\alpha_{1}+\Delta\right)$.

Following Bhattacharya and Mookherjee (1986), we put the following restrictions on the distribution function in order to analyze the effect of the MPS on the private value of adopting technology A. 
(i) Symmetry Condition (S):

The distribution of $\tilde{\beta}_{2}$ is symmetric around its mean, i.e., $F\left(\bar{\beta}_{2}+\widetilde{\beta}_{2} ; \theta\right)=1-F\left(\bar{\beta}_{2}\right.$ $\left.-\tilde{\beta}_{2} ; \theta\right)$.

(ii) Single Crossing Condition (SC):

The distribution functions of $\widetilde{\beta}_{2}$ corresponding to two different levels of riskiness $\theta$ and $\theta^{\prime}$ with $\theta>\theta^{\prime}$ intersect only once, i.e., $F\left(\tilde{\beta}_{2} ; \theta^{\prime}\right)-F\left(\tilde{\beta}_{2} ; \theta\right) \frac{\geq}{<} 0$ according to $\widetilde{\beta}_{2}>\bar{\beta}_{2}$, where $\bar{\beta}_{2}$ is the unique intersection point under condition (i).

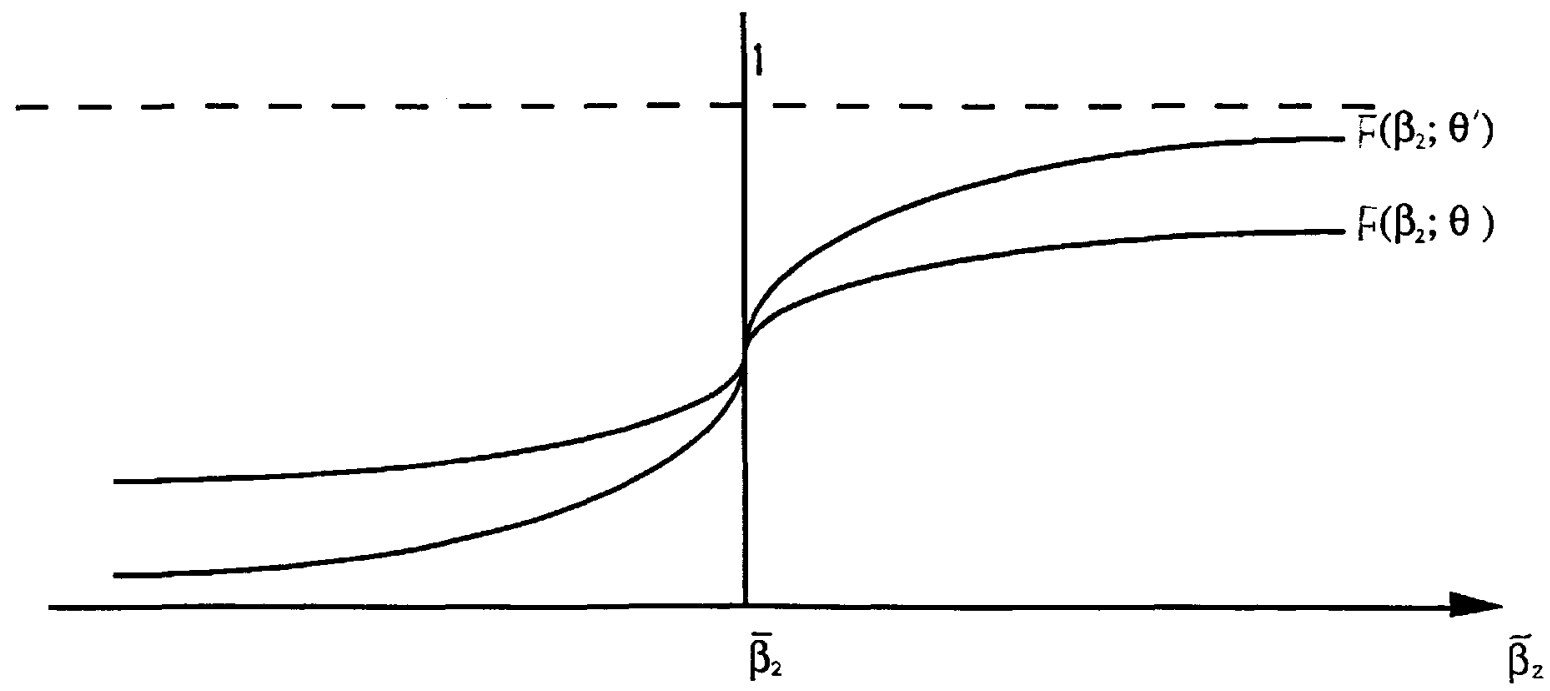

Figure 3. "Regular" Distributions Satisfying (S) and (SC)

Proposition 4. If F satisfies regularity conditions, as the MPS increases, the adoption of technology A becomes more (less) attractive for the potential early adoptor if $\bar{\beta}_{2}>(<) \alpha_{1}+$ $\Delta$.

Proof. When user 1 adopts technology A, the monopolist should give user 2 at least the value of $\alpha_{1}+\Delta$ in order to provide user 2 the incentive to buy its technology. Therefore, there will be incompatible technologies only when $\widetilde{\beta}_{2}>\alpha_{1}+\Delta$; in this case, the monopolist will charge a price of $\tilde{\beta}_{2}-\left(\alpha_{1}+\Delta\right)$. Since the probability of being stranded 
away by user 2 is $\left[1-F\left(\alpha_{1}+\Delta ; \theta\right)\right]$, the value to user 1 of adopting technology $A$ when the monopolist chooses research strategy $\theta$ is given by,

$$
\begin{aligned}
\mathrm{V}(\mathrm{A} ; \theta) & \left.=\alpha_{1}+\delta\left\{\mathrm{F}\left(\alpha_{1}+\Delta ; \theta\right)\left(\alpha_{1}+\Delta\right)+\left[1-\mathrm{F}\left(\alpha_{1}+\Delta ; \theta\right)\right] \alpha_{1}\right]\right\} \\
= & \alpha_{1}(1+\delta)+\delta \Delta \mathrm{F}\left(\alpha_{1}+\Delta ; \theta\right)
\end{aligned}
$$

By regularity conditions, $V(A ; \theta)$ is an increasing (a decreasing) function of $\theta$ if $\bar{\beta}_{2}>(<)$ $\alpha_{1}+\Delta$. Note that the private value of adoption depends only on the probability of being stranded away by the second period consumer, which is the same whether or not the technology is sponsored.

\begin{tabular}{|c|c|c|}
\hline & Private Value & Social Value \\
\hline Waiting & $\begin{array}{c}\uparrow \text { if technology B is } \\
\text { nonsponsored } \\
V(W) \quad \begin{array}{c}\text { No change if technology B } \\
\text { is sponsored }\end{array}\end{array}$ & $S(W) \uparrow$ \\
\hline Adopting & $\begin{array}{l}\uparrow \text { if } \beta>\alpha+\Delta \\
\downarrow \text { if } \beta<\alpha+\Delta\end{array}$ & $S(A) \uparrow$ \\
\hline
\end{tabular}

Proposition 2-4 and discussions above can be summarized in the following table.

Table 1. The Effects of the MPS on the Values of Adopting and Waiting

Proposition 5. The monopolist may choose a less risky research strategy than the socially optimal one if $\bar{\beta}_{2}>\alpha_{1}+\Delta$.

Proof. We construct an example as follows. $\alpha_{1}=12, \Delta=15, \bar{\beta}_{2}=30, \delta=1 . \bar{\beta}_{2}$ has a uniform distribution with support $[30-\theta, 30+\theta]$, that is, $f(x ; \theta)=\frac{1}{2 \theta} I_{[30-\theta, 30+}$ $\theta]^{(x), \text { and }}$ 


$$
\begin{aligned}
F(x ; a) & =\frac{x-(30-\theta)}{2 \theta} I_{[30-\theta, 30+\theta]}(x), \text { if } x \leq 30+\theta \\
& =1, \text { if } x>30+\theta
\end{aligned}
$$

Then,

$$
\begin{aligned}
\mathrm{V}(\mathrm{A} ; \mathrm{a}) & =\alpha_{1}(1+\delta)+\delta \Delta \mathrm{F}\left(\alpha_{1}+\Delta ; \theta\right) \\
& =24+15 \frac{(\theta-3)}{2 \theta}, \quad \text { if } \theta \geq 3 \\
& =24, \text { if } 0 \leq \theta<3
\end{aligned}
$$

Therefore, $V(W) \geq V(A ; \theta)$ if and only if $\theta \leq 5$.

The monopolist's expected profit when it chooses research strategy $\theta$ is given by

$$
\begin{aligned}
\Pi(\theta) & =2\left[\int_{\alpha}^{\infty}\left[\tilde{\beta}_{2}-\alpha\right] \mathrm{f}\left(\tilde{\beta}_{2} ; \theta\right) \mathrm{d} \tilde{\beta}_{2}\right] \\
& =2\left[\int_{30-\theta}^{30+\theta} \frac{\mathrm{t}-12}{2 \theta} \mathrm{dt}\right], \text { if } \theta \leq 5 \\
\Pi(\theta) & =\int_{\alpha+\Delta}^{\infty}\left[\tilde{\beta}_{2-}(\alpha+\Delta)\right] \mathrm{f}\left(\tilde{\beta}_{2} ; \theta\right) \mathrm{d} \tilde{\beta}_{2} \\
& =\int_{27}^{30+\theta} \frac{\mathrm{t}-27}{2 \theta} \mathrm{dt}, \text { if } \theta>5
\end{aligned}
$$

It is easy to check that the monopolist's optimal choice of $\theta$ is 5 , while the socially optimal choice is the maximum value of $\theta=30$ by proposition 2 . 
Proposition 5 contrasts with the results of Bhattacharya and Mookherjee (1986), Dasgupta and Maskin (1987), and Klette and de Meza (1986) who showed that market equilibrium involves excessively risky research projects.

\section{Within -the- Period Side Payments}

We have been assuming that side payments between generations of consumers were prohibited. Now we relax this assumption and allow consumers/ users to make side payments within the period. Note that a contract between user 1 and user 2 in the first period is still prohibited. User 2 is not able to agree on a contract (perhaps he is not yet born). The consequence of side payments is that there will always be efficiency in the second period. ${ }^{7}$

In this section, we are especially interested in whether this ex-post efficiency increases ex-ante social welfare. Let $\mathrm{V}(\mathrm{W})$ ' be the private value to user 1 of waiting and let $\mathrm{V}(\mathrm{A})^{\prime}$ be her private value adopting technology $\mathrm{A}$ in the first period. It is clear that the second period side payment does not affect the outcome if user 1 waits; that is, $\mathrm{V}(\mathrm{W})^{\prime}$ = $\mathrm{V}(\mathrm{W})$. If user 1 adopts technology $\mathrm{A}$, then user 2 will adopt the same technology if and only if $E_{2}$ occurs due to the side payment. Without side payments, inefficiencies arise only when the event $\left(E_{2}-E_{1}\right)$ occurs. If that event occurs, the total utilities attainable from bargaining is $2\left(\tilde{\alpha}_{2}+\Delta\right)$, while disagreement yields a total utility of $\left(\tilde{\alpha}_{2}+\tilde{\beta}_{2}\right)$. Therefore, the gains from trade is $2\left(\tilde{\alpha}_{2}+\Delta\right)-\left(\tilde{\alpha}_{2}+\tilde{\beta}_{2}\right)=\left(\tilde{\alpha}_{2}+2 \Delta-\tilde{\beta}_{2}\right)$, which will be divided according to the relative bargaining power of user 1 and user 2 . Let $\mu$ denote the relative bargaining power of user 1 , where $0 \leq \mu \leq 1$. Then,

$$
\begin{aligned}
\mathrm{V}(\mathrm{A})^{\prime} & \left.=\mathrm{V}(\mathrm{A})+\delta \mathrm{E}\left\{\mu\left(\tilde{\alpha}_{2}+2 \Delta-\tilde{\beta}_{2}\right)\right) \mathbf{I}_{\left(\mathrm{E}_{2}-\mathrm{E}_{1}\right)}\left[\left(\tilde{\alpha}_{2}, \tilde{\beta}_{2}\right)\right]\right\} \\
& =\alpha_{1}+\delta \Pi, \text { where } \Pi \text { is given by }
\end{aligned}
$$

\footnotetext{
${ }^{7}$ Since every relevant parameter is common knowledge in this model, the bargaining process will ensure ex-post efficiency. See Rubinstein (1982) for an example of a bargaining game where the only subgame perfect equilibrium outcome is an immediate agreement on the division of gains from trade.
} 
$\left[\int_{\mathrm{E}_{1}}\left(\tilde{\alpha}_{2}+\Delta\right) \mathrm{dG}\left(\tilde{\alpha}_{2}, \widetilde{\beta}_{2}\right)+\int_{\left(\mathbf{E}_{2}-\mathbf{E}_{1}\right)}\left[\tilde{\alpha}_{2}+\mu\left(\tilde{\alpha}_{2}+2 \Delta-\tilde{\beta}_{2}\right)\right] \mathrm{dG}\left(\tilde{\alpha}_{2}, \widetilde{\beta}_{2}\right)+\int_{\mathrm{E}_{2}^{\mathbf{c}}} \tilde{\alpha}_{2} \mathrm{dG}\left(\tilde{\alpha}_{2}, \tilde{\beta}_{2}\right)\right]$

Similarly, let $S_{M}(W)^{\prime}$ and $S_{M}(A)^{\prime}$ be the market-induced social welfare when user 1 chooses to wait or adopt technology $A$ in the first period. Then, $S_{M}(W)^{\prime}=S_{M}(W)$. If user 1 adopts technology A, then user 2 will adopt the same technology if and only if $E_{2}$ occurs.

$$
\begin{aligned}
S_{M}(A)^{\prime} & =\alpha_{1}+\delta \mathrm{E}\left\{2\left(\tilde{\alpha}_{2}+\Delta\right) \mathbf{I}_{E_{2}}\left[\left(\tilde{\alpha}_{2}, \tilde{\beta}_{2}\right)\right]+\left(\tilde{\alpha}_{2}+\tilde{\beta}_{2}\right) \mathbf{I}_{\mathrm{E}_{2}^{c}}^{c}\left[\left(\tilde{\alpha}_{2}, \tilde{\beta}_{2}\right)\right]\right\} \\
= & \alpha_{1}+\delta\left[2 \int_{\mathrm{E}_{2}}\left(\tilde{\alpha}_{2}+\Delta\right) \mathrm{dG}\left(\tilde{\alpha}_{2}, \tilde{\beta}_{2}\right)+\int_{\mathrm{E}_{2}^{c}}\left(\tilde{\alpha}_{2}+\tilde{\beta}_{2}\right) \mathrm{dG}\left(\tilde{\alpha}_{2}, \tilde{\beta}_{2}\right)\right]
\end{aligned}
$$

Since the private value of adopting technology A is increasing with the possibility of side payments, there are three cases to consider.

CASE I. V(W) $>$ V(A)' $>$ V(A)

In this case, the market outcome induces user 1 to wait in the first period by user 1 under both regimes. Therefore, social welfare does not change with the possibility of side payments. Side payment in the second period is irrelevant in this case.

CASE II. V(A)' $>V(A)>V(W)$.

In this case, the market outcome induces user 1 to adopt technology $\mathrm{A}$ in both regimes. Since the technology choice is the same in the first period and there is a possibility of efficiency gains in the second period, social welfare improves unambiguously with side payments.

CASE III. V(A)' $>$ V(W) $>V(A)$.

In this case, user 1 waits in the first period if side payments are not allowed, and she adopts technology A if side payments are allowed. Since user 2 suffers from the adoption of technology A by user 1, gains from the possibility of side payments to user 1 
come at the expense of user 2 . Social welfare depends on the relative magnitude of these two effects. The following example demonstrates the case in which ex post efficiency actually reduce $e x$ ante social welfare.

Example.

$$
\text { Let } \tilde{\alpha}_{2}=\alpha_{1}=\alpha, \tilde{\beta}_{2}=\alpha+\Delta+\varepsilon \text {, where } 0 \leq \varepsilon \leq \Delta, \mathrm{e}=\mathrm{E}(\varepsilon), \delta=1 \text {, and } \mu=1 / 2 \text {. }
$$

Then,

$$
\begin{aligned}
& \mathrm{V}(\mathrm{A})=\alpha+\alpha=2 \alpha \\
& \mathrm{V}(\mathrm{A})^{\prime}=\alpha+\alpha+1 / 2[\Delta-\mathrm{e}] \\
& \mathrm{V}(\mathrm{W})=\mathrm{E}\left(\widetilde{\beta}_{2}+\Delta\right)=\mathrm{E}(\alpha+\Delta+\varepsilon)+\Delta=\alpha+2 \Delta+\mathrm{e}
\end{aligned}
$$

The condition for $\mathrm{V}(\mathrm{A})<\mathrm{V}(\mathrm{W})<\mathrm{V}(\mathrm{A})$ ' is given by

$$
\alpha-2 \Delta<\mathrm{e}<\frac{2}{3} \alpha-\Delta
$$

The market-induced social welfare when user 1 adopts technology A or waits is given by

$$
\begin{aligned}
& S_{M}(A)=E\left[\alpha+\left(\alpha+\widetilde{\beta}_{2}\right)\right]=3 \alpha+\Delta+e \\
& S_{M}(A)^{\prime}=\alpha+2(\alpha+\Delta)=3 \alpha+2 \Delta \\
& S_{M}(W)=S_{M}(W)^{\prime}=E\left[2\left(\widetilde{\beta}_{2}+\Delta\right)\right]=2(\alpha+2 \Delta+e)
\end{aligned}
$$

The condition for $S_{M}(W)>S_{M}(A)$ is given by

$$
\text { e }>\frac{1}{2} \alpha-\Delta
$$

If conditions (9) and (10) are satisfied, the possibility of side payments changes the market outcome from (W, B) to (A,A) and reduces the overall social welfare. Even though user 1 always benefits from the possibility of side payments, in this case, she does so at the expense of user 2. In this case, the ex -post efficiency of side payments hurts user 2 .

This result has significant implications for public policy related to standardization. Suppose that a government agency has the power to impose mandatory compatibility of new and old technology. For instance, the FTC recently decided to require that any transmission standard for high-definition TV (HDTV) be compatible with the current 
NTSC standard receivers. ${ }^{8,} 9$ One danger of this kind of policy is that early users may adopt inferior technology too soon, in anticipation of public policy which guarantees that they will not be stranded away. Given the installed base of inferior technology, the best ex post policy might be a mandatory compatibility requirement for new technologies.

However, as long as this requirement puts technical constraints on the development of new technology, it may be ex ante welfare-reducing.

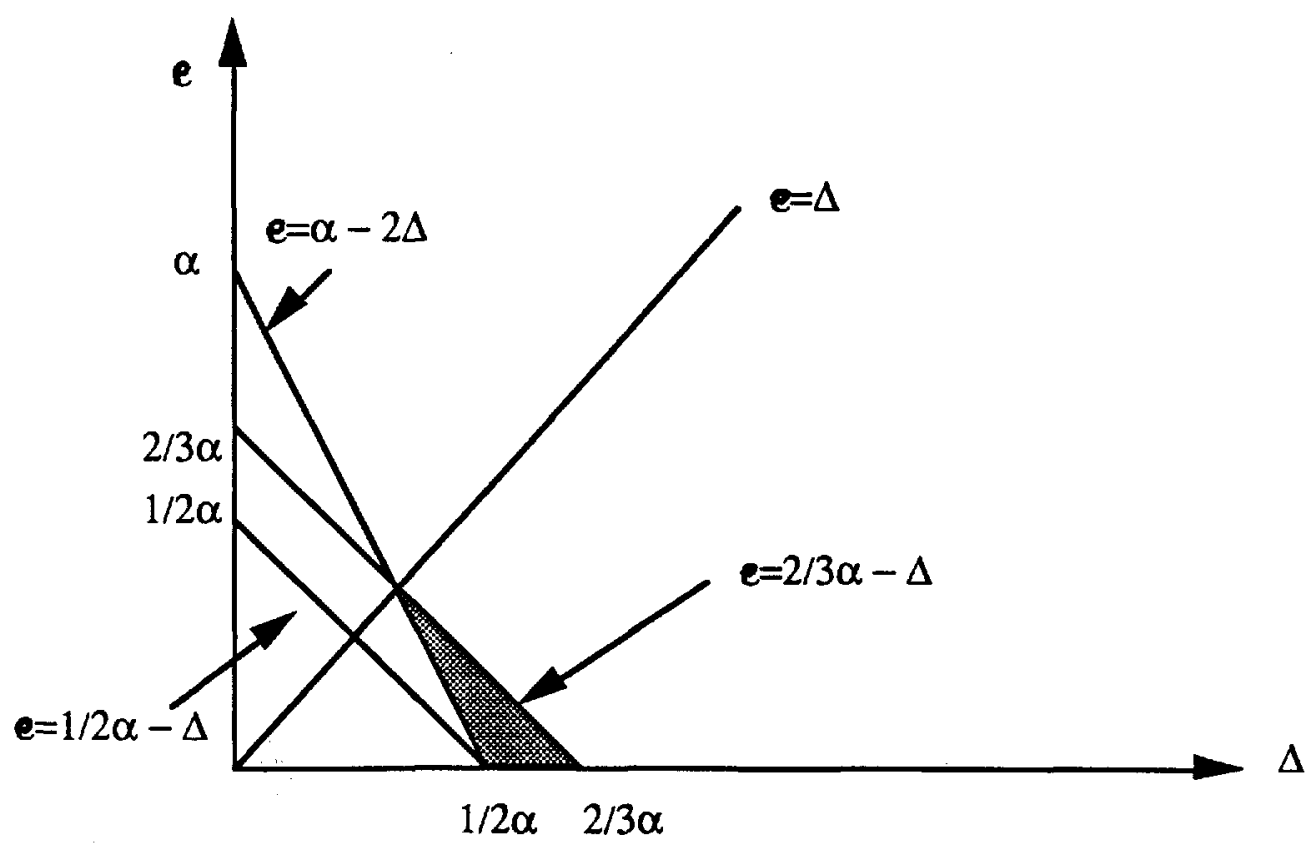

Figure 2. Ex Ante Efficiency vs. Ex Post Efficiency

${ }^{8}$ Another possible motive for this decision might be to give domestic firms a second chance to catch up with Japanese and European firms that are far ahead in this field. Since the transmission methods developed and proposed by foreign countries are incompatible with the existing NTSC standard, by requiring "backward" compatibility, the policy can put the U.S. on an equal footing in the development game.

9In contrast, the Federal Communications Commission adopted a color television system that was incompatible with the existing black and white system, even though the decision was overridden by an order of the Director of Defense Mobilization. See Katz and Shapiro (1986) where they attribute this example to S. Besen. 


\section{Concluding Remarks}

A simple model of technology adoption, with irreversible technology choice and network externalities, was presented. The growing literature on compatibility and network externalities has concentrated on analyzing the coordination problems of standardization, and if standardization is chosen, determining the standard. Even when the problem is examined in a dynamic setting, previous research considers only the unexpected arrival of a new and perhaps superior technology. Therefore, the option of waiting in a technology adoption decision is not considered explicitly. The value of the waiting option is explicitly analyzed in the irreversible investment literature, but the decisions are made in a competitive economy setting, utilizing a decision-theoretic framework without externalities. This paper combines these two elements and explores the implications of network externalities in the adoption of irreversible technology.

In our model, the focus has been on the between-period user heterogeneity arising from the timing of adoption decisions. All consumers have the same preference (withinperiod homogeneity) towards the value of technologies as long as no prior commitment to any technology has been made. However, there is an incongruity in preferences between generations of users since potential users arrive sequentially. Early arrivers have a longer flow of benefits from the earlier adoption of a technology. We demonstrated that there is a tendency towards too early adoption of technologies compared to the social optimum. We also found that the sponsor of a new emerging technology might choose too safe a research strategy.

One potential extension of the model would explore the timing of standardization when there are conflicting technological preferences in the same period (within-period heterogeneity), especially when there is asymmetry in the valuation of compatibility. 


\section{References}

Balcer, Y. and Lippman, S., "Technological Expectations and the Adoption of Improved Technology," Journal of Economic Theory (34), 1984, pp.292-318.

Baldwin, C.,"Optimal Sequential Investment When Capital is Not Readily Reversible," Journal of Finance (37), June 1982, pp.763-782.

Banerjee, A. and Summers, L., "Frequent Flyer Programs and Other RoyaltyInducing Economic Arrangements," H.I.E.R. Discussion Paper 1337, 1987.

Besen, S. and Saloner, G., "Compatibility Standards and the Market for Telecommunications Services," Rand Corporation Paper P-7393, May 1988.

Bhattacharya, S. and Mookherjee, D., "Portfolio Choice in Research and Development," Rand Journal of Economics (17), Winter 1986, pp.594-605.

Choi, J., "Network Externality, Compatibility Choice, and Planned Obsolescence," mimeo. Harvard University, April 1990.

Dasgupta, P. and Maskin, E., "The Simple Economics of Research Portfolios," Economic Journal (97), 1987, pp.587-595.

Dasgupta, P. and Stiglitz, J., "Uncertainty, Industrial Structure and the Speed of R\&D," Bell Journal of Economics (11), 1980, pp.1-28.

David, P., "CLIO and the Economics of QWERTY," American Economic Review: Papers and Proceedings (75), 1985, pp.332-337.

Farrell, J., "Competition with Lock-In," GTE Lab., 1985.

Farrell, J. and Saloner, G., "Standardization, Compatibility, and Innovation," Rand Journal of Economics (16), Spring 1985, pp.70-83.

, "Installed Base and Compatibility: Innovation, Product Preannouncements, and Predation, American economic Review (76), December 1986, pp.940-955.

, "Competition, Compatibility, and Standards: The Economics of Horses, Penguins and Lemmings," in Product Compatibility as a Competitive Strategy, ed. H. L. Gabel., 1987, Amsterdam: North Holland.

, "Coordination through Committees and Markets,"Rand Journal of Economics (19), Summer 1988, pp.235-252.

Katz, M. and Shapiro, C., "Technology Adoption in the Presence of Network Externalities," Journal of Political Economy (94), 1986, pp.822-841. 
"Product Introduction with Network Externalities," Journal of Industrial Economics, Oxford Economic Papers (40), 1992, pp.5584.

Klemperer, P., Markets with Consumer Switching Costs," Quarterly Journal of Economics (102), 1985, pp.375-394.

Klette, T. and de Mezza, D., "Is the Market Biased against Risky R\&D?" Rand Journal of Economics (17), 1986, pp.133-139.

McDonald, R. and Siegel, D. R., "The Value of Waiting to Invest," Quarterly Journal of Economics (101), November 1986, pp.707-728.

Pindyck, R.S., "Irreversible Investment, Capacity Choice, and the Value of the Firm," American Economic Review (78), December 1988, pp.969-985.

Rosenberg, N., Inside the Black Box: Technology and Economics," Cambridge University Press, 1982.

Rothschild, M. and Stiglitz, J., "Increasing Risk: I. A Definition," Journal of Economic Theory (2), 1970, pp.225-243.

Rubinstein, A., "Perfect Equilibrium in a Bargaining Model," Econometrica (50), 1984, pp. 97-109.

Waldman, M., "A New Perspective on Planned Obsolescence," Yale School of Organization and Management working Paper No. 532, November 1989, also forthcoming in Quarterly Journal of Economics. 